\title{
PROJECT-BASED TEACHING AND ITS USAGE IN TURKISH INSTRUCTION
}

\author{
Kemal Zeki ZORBAZ*
}

\author{
Mehmet Akif ÇEÇEN**
}

\begin{abstract}
Project-based teaching is a teaching strategy which basically considers students' activities, relies on students' designs and aims at teaching through projects.

Developed in the beginning of XX'th century, Project-based teaching has been a specific teaching strategy through studies of Dewey and Kilpatrick and opinions of Piaget, Vygotsky and Bruner. Project-based teaching aims to transform students in the learning-teaching process from taker position into individuals researching, examining and problem solving using knowledge acquired. Implementation steps of project-based teaching are determination of goals and subject, composition of teams, gathering and organization of knowledge, conclusion of project and evaluation of project.

In this study, by means of literature scanning; theoretical basics, implementation steps, superiority, limitations and position in Turkish instruction of Project-based teaching are studied.
\end{abstract}

Key words: Project based teaching, Turkish instruction.

\footnotetext{
*Res. Assist., Mustafa Kemal University, Educational Faculty, kzorbaz@mku.edu.tr

** Res. Assist. Dr., Inonu University, Educational Faculty, akifcecen@ gmail.com
} 


\section{SUMMARY}

Purpose and Significance: In this study, by means of literature scanning; theoretical basics, implementation steps, superiority, limitations and position in mother language teaching of Project-based teaching are studied.

Methods: This study has a descriptive character in point of studying origin process of Project-based teaching and its importance in mother language teaching through literature scanning.

Results: Project-based teaching is a teaching strategy which basically considers students' activities, relies on students' designs and aims at teaching through projects.

Developed in the beginning of XX'th century, Project-based teachings have been a specific teaching strategy through studies of Dewey and Kilpatrick and opinions of Piaget, Vygotsky and Bruner. Project-based teaching aims to transform students in the learning-teaching process from taker position into individuals researching, examining and problem solving using knowledge acquired.

Implementation steps of project-based teaching are determination of goals and subject, composition of teams, gathering and organization of knowledge, conclusion of project and evaluation of project.

In this study, by means of literature scanning; theoretical basics, implementation steps, superiority, limitations and position in mother language teaching of Project-based teaching are studied. It is very important that Project is well designed and planned. Duties of students and responsibilities of everyone should be determined very well when Project is designed. Getting the project designed others should be banned and students should be encouraged to work even if it is completed or false. In the case of successful projects, students' selfconfidence will increase. Successful projects teach students deciding on their own in important issues. It provides participation of students into group working and cooperation based learning activities.

It is important in Project-based teaching strategy that students form knowledge on their own which is suitable for teaching programs prepared through configurive comprehension. In this context, students learn through living and taking active role in learning. In point of a product submission of students, Project-based teaching will contribute students to gain self-confidence and making decisions on their own. In this context, it will also contribute them to become socialized with regard to acquiring working abilities with their contemporaries or on their own.

It will be useful to execute Project-based teaching through unit or theme. Particularly, theme based Turkish Teaching Program will provide Project-based teaching easy implementation. Planning and developing of the project should not be thoroughly left to teachers and students. Subject of the lesson and acquisitions determined in the program, which will be very effective and productive, should be determined by experts through experimental studies. Teachers should implement the project, which is developed by experts, through making little differences suitable for students and themselves. 


\section{PROJE TABANLI ÖĞRETIM VE TÜRKÇE ÖĞRETIMINDE KULLANIMI}

Kemal Zeki ZORBAZ*

\author{
Mehmet Akif ÇEÇEN**
}

\section{$\ddot{O} z$}

Proje Tabanlı Öğretim, öğrencilerin etkinliğini esas alan, öğrencilerin tasarımına dayanan ve öğretimi projeler yoluyla gerçekleştirmeyi hedefleyen bir öğretim stratejisidir.

XX. yüzyılın başlarında ortaya çıkan Proje Tabanlı Öğretim, Dewey ve Kilpatrick'in çalışmaları ve Piaget, Vygotsky ve Bruner'in görüşleri doğrultusunda belli bir öğretim stratejisi hâline gelmiştir. Proje Tabanl Ögretim, öğrenme-öğretme sürecinde öğreneni; alıcı konumundan, inceleyen, araştıran ve elde ettiği bilgileri kullanarak sorun çözen, üretici bireyler haline getirmeyi hedeflemektedir. Proje Tabanlı Ögretimin uygulama basamakları; hedeflerin oluşturulması ve konunun belirlenmesi, takımların oluşturulması, bilgilerin toplanması ve örgütlenmesi, projenin sonuçlandırılması, projelerin değerlendirilmesi şeklindedir.

$\mathrm{Bu}$ çalışmada alan yazını taraması yoluyla Proje Tabanlı Öğretimin kuramsal temelleri, uygulama basamakları, üstünlükleri, sınırlılıkları ve Türkçe öğretimindeki yeri ifade edilmeye çalışılmıştır.

Anahtar Sözcükler: Proje tabanlı öğretim, Türkçe öğretimi.

\footnotetext{
*Araş. Gör., Mustafa Kemal Üniversitesi, Eğitim Fakültesi, kzorbaz@mku.edu.tr

*** Araş. Gör. Dr., İnönü Üniversitesi, Eğitim Fakültesi, akifcecen@gmail.com
} 


\section{Giriş}

Günümüzde bilginin katlanarak artmasına paralel olarak bilgiye ulaşma adına öğretim yöntemleri de değişiklik göstermektedir. Artık bilgiyi öğretme değil, öğrenmeyi öğretme, bilginin nasıl elde edileceğini öğretme, eğitimin ana prensipleri hâline gelmektedir. Bunun için öğrencinin, öğretmen rehberliğinde, yaparak ve yaşayarak öğrenmesini sağlamayı amaçlayan öğretim stratejileri doğmuştur. Bu stratejilerden biri de Proje Tabanl Ögretim'dir.

Proje, Türkçe Sözlük'te (TDK, 2005), tasarlanmış şey, tasarı olarak ifade edilmektedir. Eğitim açısından projeler; öğrencilerin ilgisini çeken, eğitim açısından önemli olan ve ögrencilerin etkinliklerle uğraşması ile meydana gelen yoğun deneyimler olarak ifade edilebilir (Fleming, 2000: 1). Saban'a göre (2002: 254-255) projeler, öğrencilerin genellikle somut bir ürüne ulaşmak için tek başına veya küçük gruplar hâlinde bir görev üzerinde uzun bir süre bireysel olarak veya birlikte çalışmalarıdır. Buna göre Proje Tabanlı Öğretim, öğrencilerin etkinliğini esas alan, öğrencilerin tasarımına dayanan ve ögretimi projeler yoluyla gerçekleştirmeyi hedefleyen bir ögretim stratejisidir.

Proje Tabanlı Öğretim; İngilizce yayın ve tezlerde daha çok Proje Tabanlı/Temelli Öğrenme (Project-Based Learning) olarak geçmekle birlikte Proje Tabanlı Öğretim (Project-Based Teaching/Instruction), Proje Tabanl Model (Project-Based Model), Proje Tabanlı Yaklaşım (Project-Based Approach) olarak da ifade edilmektedir.

Proje tabanlı öğretim; Türkçe yayın ve tezlerde ise daha çok öğrenci açısından adlandırılabilecek Proje Tabanlı Öğrenme (Erdem ve Akkoyunlu, 2002; Vaiz, 2003, Seloni, 2005; Yılmaz, 2006; Çiftçi, 2006; Özdemir, 2006) şeklinde geçmekle birlikte Projeye Dayalı Öğretim (K1liç, 2004), Proje Tabanlı Ögrenme Modeli (Özdener ve Özçoban, 2004; Yavuz, 2006), Proje Temelli Ögrrenme Yöntemi (Girgin Balk1, 2003), Proje Tabanlı Ögrrenme Yaklaşımı (Demirhan, 2002; Yurtluk, 2003), Proje Yöntemi (Taşpınar, 2005: 100), Proje Çalışması (Saban, 2002: 254) adlarıyla ele alınmıştır. Bu çalışmada, bir öğretim stratejisi olması, bu stratejinin dayanak olarak bir projeyi esas alması ve öğretmen rehberliğinde uygulanması sebebiyle sözü edilen adlandırmalar içerisinden Proje Tabanlı Öğretim ismi tercih edilmiştir.

Proje tabanlı öğretim, öğrenciyi öğretme-öğrenme sürecinin merkezine alan, gerçek yaşamın konularına ve uygulamalarına yer veren bir öğrenme yaklaşımıdır. Öğrencilerin problem çözme becerilerini geliştirdiği için daha çok uygulama, analiz ve sentez düzeyindeki hedeflerin gerçekleşmesinde kullanılır. Bu öğrenme yaklaşımında öğrenciler, grup çalışmalarının yanı sıra bağımsız çalışmalar da yürütmekte ve öğrenmeyi yapılandırıp tasarlamaktadırlar (Demirel, 2003: 237). 


\section{Proje Tabanlı Öğretimin Dayandığı Kuramsal Temeller}

Proje Tabanlı Öğretim, Fransa'da 18. yüzyılda Akademi Royale d'Architecture öğrencilerinin, çalışmalarını ortak, orijinal ve öğretmen desteği olmadan kendi başlarına yürütmek zorunda olmalarından doğmasına (Knoll 1988'den aktaran Yıldız, 2003: 39-40) karşılık sistemli olarak ortaya çıkışı XX. yüzyıl başlarına rastlar.

Friedrich Froebel, William James, G. Stanley Hall, Francis Wayland Parker, John Dewey ve William Kilpatrick gibi önde gelen birçok pedagog, çocukların eğitiminde yeni bir yönelime ihtiyaç olduğunu söylemişler ve çocuk merkezli yeni bir eğitim modeli önermişlerdir. Yeni eğitim modelinin başlıca amacı çocuğun ihtiyaç ve ilgilerini temele almaktı. Kısaca bu modelde çocuk kendi eğitimini belirlemede etkin rol oynuyordu. Eğitimci liderlerin öne sürdüğü bu fikir gerçekten de devrimseldi ve birçok eğitim hareketinde önemli bir ilerleme sağladı. (Burr, 2001'den akt. Çiftçi, 2006: 31).

Eğitimin yaşantıya dayalı olması gerektiğini belirten Dewey, hedeflere yönelik doğrudan ögretim yerine, içinde sürekli yaşantı gerektiren etkinliklerin yer aldığı gelişimi ve ilerlemeyi sağlayan eğitim modellerinin önemini vurgulamıştır. Dewey'e göre, çocuklara dünyayla nasıl kaynaşacakları ve bütünleşecekleri uygulamalı olarak öğretilmeli ve yaşam boyu kendi bilgilerini çeşitli etkinlikler yoluyla inşa edebileceklerine dair onlara güven duyulmalıdır. Dewey'e göre, öğretmen ve çocuk, eğitici süreç boyunca önemli ve kapsamlı amaçlar geliştirmek için birlikte çalışmalıdırlar. Amaçlar, etkinliğin kendi doğasında var olmalıdır ve öğretmenin beklentilerinden değil, etkinliğin kendisinden türemelidir. Öğretmen, amaçları tanımlayarak etkinlikler sırasında çocuğun kendi yaptıklarına ve öğrendiklerine ilişkin farkındalığını arttırmalıdır. Dewey, etkinlikler sırasında amaçlara ek olarak merak ve disiplinin de önemine dikkat çekmektedir. Küçük çocuklar doğal bir meraka sahiptirler ve açık fikirli olmaya eğilimlidirler. Öğretmen, bu noktadan hareketle, merak uyandıran farklı bir etkinlik yoluyla, hedef etkinliği öğrenciler için daha da ilgi çekici hâle getirmelidir (Alnık ve Yılmaz, 2004: 94-95).

Dewey'in çalışmalarını bir adım daha ileriye taşıyan Kilpatrick'in 1918'de yayımladığı "proje metodu" başlıklı makalesi eğitim alanında yeni bir heyecanın başlangıcı olmuştur. Kilpatrick bu makalesinde proje kelimesini kullanarak projeyi tanımlamıştır. Çünkü bu dönem boyunca eğitim diline göre proje birçok yolla tanımlanıyordu ve bu yüzden karışıklıklara ve yanlış anlaşılmalara neden oluyordu. Kilpatrick, bu makalesinde kendinin ve Dewey'in fikirlerini yapılandırmış; projelerin, çocukların makul bir aktiviteyi yapabilmeleri ve dünyayı daha derinden anlamaları yolunda kullanılması gerektiğini iddia etmiştir (Niesz, 2003 ve Williams, 1998'den akt. Çiftçi, 2006: 33). 
Dewey'in ve Kilpatrick'in bu çalışmalarından sonra proje stratejisine olan ilgi zamanla azalmıştır. Bruner'in öğretme teorisi ile birlikte yeniden gündeme gelen proje stratejisi, Gardner'in çoklu zekâ teorisiyle birlikte önemi artan bir strateji konumuna yükselmiștir.

Bugünkü anlamda proje tabanlı ögretimde;

$>$ Piaget'nin şema teorisi,

$>$ Vygotsky'nin (yakınsak gelişim alanı içerisinde değerlendirilen) bir yetişkin ya da akran grubu yardımıyla öğrenme düşüncesi,

$>$ Dewey’in öğrenci etkinliğine dayalı öğrenme düşüncesi,

$>$ Bruner'in keşif yoluyla öğrenme düşüncelerinin bir bütün halinde etkisi vardır, denebilir.

Proje tabanlı öğretim, bireysel olarak ya da küçük gruplar aracıllğıyla problemlerin çözümünü amaçlayan bir öğretim yaklaşımıdır. Bir başka ifadeyle, öğrenme-öğretme sürecinde öğrenenin, pasif alıcı konumundan; araştıran, inceleyen, bilgiye ulaşan ve elde ettiği bilgileri kullanarak sorun çözen, bağımsız düşünen, yaratıcı bireyler hâline getirmesini temele alan bir öğrenme yaklaşımıdır (Schmidt ve Fisher, 1992'den akt. Yılmaz, 2006: 34).

\section{Stratejinin Kullanımı}

\subsection{Ana Hatlarıyla Proje Tabanlı Öğretim}

Proje tabanlı öğretim, eğitimdeki çağdaş yaklaşımlarda ağırlıklı olarak karşımıza çıkan, öğrenen merkezli ve öğrenenin aktif olarak etkinliklerde yer aldığı, grupla çalıştığı, yaratıcı düşünme becerilerini ve olumlu risk alma davranışlarını geliştiren bir yapıdadır. Bugünün insanı, geçmişten farklı olarak çağa ayak uydurmak, gelişmiş araç ve gereçlerle barışık yaşamak, onlardan yararlanmak zorundadır. Günümüzde çeşitli meslek alanları; yaratıcılık, iletişim, problem çözme ve takımla çalışma gibi, öğrencilerin iş ve yaşam becerilerini merkeze alan proje tabanlı öğretim ortamlarını kullanmalarını önermekte ve her türlü becerilerle donanmış bireyleri talep etmektedir (Kaptan ve Korkmaz, 2002: 165).

Proje tabanlı öğretim; hem bireysel olarak hem de grup içinde sorumluluk alabilme yeteneğini gerektiren, öğrencilerin farklı disiplinleri içeren gerçek dünya problemlerini, hazırladıkları iş birlikçi öğrenme projeleriyle ilişkilendirdikleri, yaratıcı gücü geliştiren, öğrenciyi araştırma yapmaya teşvik eden, öğrenci merkezli, sınıf içi ve sınıf dışındaki aktiviteleri içeren bir modeldir (Yavuz, 2006: 16). 
Proje tabanlı öğretim için hedefler;

$\checkmark$ karmaşık zihinsel problemleri çözebilme,

$\checkmark$ iş birliği içinde çalışabilme,

$\checkmark$ karşılaşılan sorunlara farklı çözüm önerileri getirebilme,

$\checkmark \quad$ yaptığı çalışmaların sonucunda bir ürün ortaya koyma ve

$\checkmark \quad$ uzun vadede hayat boyu öğrenen, özerklik kazanmış, problem çözebilen bireyler yetiştirmektir (Yurtluk, 2005: 70).

Proje tabanlı öğretim; tasarı geliştirmeye, planlamaya, kurgulamaya dayalı bir öğrenme anlayışı olarak karşımıza çıkmaktadır. Tasarlamaya ya da kurgulamaya dayalı bir öğrenme anlayışı ise her şeyden önce, ürünü değil süreci biçimlendirmeye yönelmek durumundadır. Çünkü tasarılar ya da kurgular, değişmeye açik düşünce yapılarıdır. Anlayışı oluşturan temel sözcüklerden biri olan "tabanlı" sözcügü de projenin, bir hedef değil, bir alt yapı unsuru olduğunu vurgulamakta ve süreç yönelimli yapılanmaya işaret etmektedir (Erdem, 2002: 173).

Proje tabanlı öğretim, günümüzde eğitim sistemlerinin alması gereken biçimi göstermek için özenle seçilmiş üç temel kavramdan oluşmaktadır. Bu kavramlardan birisi ögrenme kavramıdır ki dikkati öğretene değil öğrenene çekmek açısından son derece önemlidir. Bir diğeri proje kavramıdır ve proje; tasarı ya da tasarı geliştirme, hayal etme, planlama anlamına gelmektedir. Bu kavram, öğrenmenin projelendirilmesi yani yönlendirilmesi anlayışına işaret etmekte, tekil öğrenmeden çok belli bir amaca dönük ilişkisel öğrenmeyi vurgulamaktadır. Projeyi bir hedef olarak değil, alt yapı unsuru olarak ele almakla da proje tabanlı öğrenme; öğrenmenin ürün değil süreç boyutunu vurgulamakta ve öğrenmeye, öğrenene özgü bir yap1 kazandırmaktadır (Erdem ve Akkoyunlu, 2002: 3).

Proje tabanlı öğretim, temelde aşağıdaki becerilerin ve özeliklerin gelişmesine olanak sağlayabilir (Yurtluk, 2005: 73):

> Grupla birlikte çalışma becerileri,

> Yaşam becerileri (toplantı yürütme, plan yapma, bütçe kullanma vb.),

$>$ Bilişsel işlem becerileri (karar alma, eleştirel düşünme, problem çözme vb.),

$>$ Kendi kendini yönetme becerileri (amaçları belirleme, görevleri organize etme, zaman yönetimi vb.),

$>$ Tutumlar (öğrenme sevgisi, ileri eğitim aşamalarına isteklilik),

$>$ Eğilimler (kendini yönlendirme, başarma duygusu),

$>$ İnançlar (kendi kendine yeterlik) gibi. 
Yukarıda sıralanan maddeler, proje tabanlı öğretimde hedeflenenin yalnızca öğretim olmadı̆̆ına işaret etmektedir. Proje tabanlı öğretim, öğreneni pasif konumdan aktif bir konuma çıkardığı, öğrenene yaparak öğrenme becerisi kazandırdığ 1 gibi öğrenmeye ve öğretime de yeni bir nitelik kazandırmaktadır.

\subsection{Proje Tabanlı Öğretimin Uygulama Aşamaları}

Proje tabanlı öğretimde temel adımlar şunlardır (Moursund, 1999'dan akt. Erdem ve Akkoyunlu, 2002: 4):

1. Hedeflerin belirlenmesi.

2. Yapılacak işin ya da ele alınacak konunun belirlenip tanımlanması.

3. Takımların oluşturulması.

4. Sonuç raporunun özelliklerinin ve sunuş biçiminin belirlenmesi.

5. Çalı̧̧ma takviminin oluşturulması.

6. Kontrol noktalarının belirlenmesi.

7. Değerlendirme ölçütlerinin ve yeterlik düzeylerinin belirlenmesi.

8. Bilgilerin toplanmas1.

9. Bilgilerin örgütlenip, raporlaştırılması.

10. Projenin sunulmas1.

$\mathrm{Bu}$ temel adımlar birleştirilerek proje tabanlı öğretimin uygulama aşamaları şu şekilde ifade edilebilir:

\section{A. Hedeflerin Olușturulması ve Konunun Belirlenmesi}

Bir projede öncelikle bu proje ile nelerin hedeflendiği, edinilecek davranışlar ve kazanımlar belirlenir. Daha sonra bu hedeflere ulaştıracak konu tespit edilir.

Proje tabanlı öğretim yaklaşımının en zor ve en önemli aşamalarından biri proje konusunu belirlemedir. Projelere konu seçimi dikkat ve titizlik isteyen bir öneme sahiptir. Proje tabanlı öğretim yaklaşımında öğrenenler projeyi seçme hakkına ve küçük gruplarda veya bütün sınıf tartışmalarında, araştırmak istedikleri konuları belirlemede söz hakkına sahip olmalıdırlar. Proje seçme bir öğrencinin yeteneğini ve gelişimini göstermede ve eğitim hedeflerini belirlemede karşılaşacağı en güzel durumlardan biridir. Projeler mutlaka hayatta karşılaşılabilecek durumlarla ilgili olmalı ve öğrenciler, böylece neyi niçin öğrendiklerini mutlaka anlamalıdırlar (Çiftçi, 2006: 47). 


\section{B. Takımların Olușturulması}

Proje tabanlı öğretim; bireysel, tüm sınıfla ya da takım çalışmaları şeklinde yürütülebilir. Bireysel çalışmalar bağımsız çalışma becerilerinin, takım çalışmaları ise iş birliği içinde çalışma becerilerinin gelişmesini sağlayacaktır. Takımlar öğrencilerle birlikte oluşturulmalı, takımların 4-5 kişilik ve sahip olunan beceriler açısından heterojen yapıda olmasına özen gösterilmelidir. Takım sayısı, ele alınan proje konusuna ve sınıf mevcuduna göre değişebilir (Erdem, 2002: 166).

\section{Bilgilerin Toplanması ve Örgütlenmesi}

Proje tabanlı öğretim çalışmalarına başlanmadan önce iyi, başarıyla sonuçlanmış, istenilen hedeflere ulaşmış, kaliteli bir proje için önceden yapılması gereken en önemli şey projenin planının hazırlanması, proje sürecinin etkili yönetimi ve takibidir. Planlama, özellikle daha önce proje çalışmaları yapmamış öğretmenlerin bu süreçteki kaygılarını ortadan kaldırmak, daha sonra gelecek projelere bir temel oluşturması için de etkili bir yoldur (Çiftçi, 2006: 49). Planlama yapılırken projenin hedefleri, projenin kaç hafta süreceği, hangi temel kaynaklardan, kaynak kişilerden ya da kurumlardan faydalanılacağ 1 , her hafta hangi etkinliklerin yapılacağ 1 , hangi haftalarda ara değerlendirme yapılacağı, son değerlendirme ve proje sunumunun ne zaman yapılması gerektiği ayrıntılı bir biçimde ifade edilmelidir.

\section{Projenin Sonuçlandırılması}

$\mathrm{Bu}$ bölüm öğrenmeyi ve proje boyunca olan deneyimleri değerlendirmeyle ilgilidir. Çocuklar ve öğretmen projelerini diğerleri ile paylaşma şansı veren sonuçlandırma etkinlikleri düzenlerler. Burada diğer sinıflara, ailelere ve komitelere sunumlar yapılır. Çocuklara mutlaka çalışmalarını sunma şansı verilmeli ve deneyimlerini paylaşacakları insanlar davet edilmelidir. Çalışmaları paylaşmak için davet etmenin yanında, çocukların öğrendiklerinden neler çıkardıkları, sentezledikleri ve nasıl tepki gösterdiklerine imkân sağlamak da oldukça önemlidir (Çiftçi, 2006: 53).

\section{E. Projelerin Değerlendirilmesi}

Projelerin değerlendirilmesinde özellikle performans değerlendirme ölçekleri (rubrikler) ve ürün dosyalarının (portfolyo) kullanılması daha uygundur.

Projede öğrenci performansının değerlendirilmesi; toplantılara, dönem boyunca kurs üyeleri ve takımlar arasındaki tartışmalara, sınıftaki öğrenci çalışmalarının gözlenmesine, grup rapor ve evraklarına, kişisel raporlara ve kurs sonunda bir sergiye veya multimedya sunumlara dayalıdır. Öğretmenler kontrol listeleri, portfolyolar, değerlendirme formları gibi araçlar düzenlerler ve öğrencilerin aktivitelerini karşılaştırmak için bunları kullanırlar (Çiftçi, 2006: 74). 


\subsection{Stratejinin Üstünlükleri ve Sınırlılıkları}

\section{A. Stratejinin Üstünlükleri}

Stratejinin üstünlükleri ile ilgili olarak şunlar söylenebilir (Saban, 2002: 257; Yavuz, 2006: 23-24)):

1. Projeler, öğrencilere pratik deneyimler kazandırır.

2. Projeler, okulda öğrenilen bilgilerin gerçek hayatta sınanmalarına olanak tanir.

3. Projelerin başarı ile tamamlanmaları halinde, öğrencilerin kendilerine olan güvenleri artar.

4. Projeler, öğrencilerin öğrenmek için motivasyonlarını arttırır ve onların daha sonraki projeleri için yeni ilgi alanları geliştirmelerini sağlar.

5. Projeler, öğrencilere önemli konularda kendi başlarına karar almalarını öğretir.

6. Projeler, öğrencilerin kendi öğrenmelerinden sorumlu olmalarını sağlar.

7. Öğrencilerin, grupla çalışma ve iş birliğine dayalı öğrenme etkinliklerine katılımını sağlar.

8. Öğrencilerin bilgilerini yansıtmaları ve katılımları için çoklu yollar önerir.

\section{B. Stratejinin Sinırlılıkları}

Proje Tabanlı Öğretim stratejisinin sınırlılıkları şunlardır (Saban, 2002: 257; Çiftçi, 2006: 62):

1. Öğrencilerin kendilerine verilen bir projeyi tamamlamaları uzun zaman alabilir.

2. Eğer projeler öğretmen gözetimi dışında gerçekleştirilirse, önemli problemlerle karşı karşıya kalınabilir.

3. Bazı öğrenciler, kendilerine ilginç gelebilecek proje konuları bulmada zorlanabilir.

4. Öğretmenler proje çalışmaları sırasında hangi öğrencinin daha az veya hangi öğrencinin daha çok çalıştığını anlayamayabilir.

5. Öğrencilerin ulaştıkları kaynakları ne şekilde elde ettikleri bilinemeyebilir. Çünkü öğrenciler çalışmalarını hazır olarak bulabilirler ya da bir başkasına yaptırabilirler. 


\section{Proje Tabanlı Öğretim Stratejisine İlișkin Çalıșmalar}

Proje tabanlı ögretim, özellikle öğrenci merkezli olması nedeniyle son yıllarda üzerinde birçok çalışmanın yapıldığı bir alan olmaya başlamıştır. Hedeflenen projelerin nasıl uygulanabileceği konusunda fikir verebilmesi açısından konu ile ilgili çalışmaların bir kısmı aşağıda özetlenmiştir. Çalışmalar özetlenirken araştırmacıların stratejiyle ilgili özgün adlandırmaları korunmuştur:

Toci'nin (2000), çalışmasında teknolojiyle desteklenmiş proje tabanlı öğrenme ortamının öğrenenlerin iç motivasyonlarına etkisi araştırılmıştır. Çalışmada beş ve altıncı sınıf öğrencilerinden bir grup üzerinde sekiz aylık bir çalışma sonunda, uygun tasarlanmış olan öğrenme ortamlarının öğrencilerin içsel motivasyonlarına olumlu yönde etkide bulunduğu belirlenmiştir.

Demirhan'ın (2002) yaptı̆̆ deneysel çalışmada İlköğretim 3. sınıf Hayat Bilgisi dersine ait bir ünitede gerçekleştirilen çalışma sonucunda proje tabanlı öğretimin Hayat Bilgisi dersinde öğrencilerin etkin katılımlarını, araştırma yaparak bilgiye ulaşmalarını, araştırmalarını sunmalarını desteklediği belirlenmiş ve bir ürün ortaya çıkarmanın, öğrencilerin yaşama hazır duruma gelmelerini sağlayacağı belirtilmiştir.

Korkmaz (2002), çalışmasında fen eğitiminde proje tabanlı öğrenmenin ilköğretim yedinci sınıf öğrencilerinin yaratıcı düşünme, problem çözme ve akademik risk alma düzeylerine etkisini araştırmıştır. Araştırma sonunda proje tabanlı öğrenmenin yaratıcı düşünme, problem çözme becerisi ve akademik risk alma düzeyleri yönünden olumlu etkileri olduğu tespit edilmiştir.

Girgin Balkı (2003), çalışmasında proje temelli öğrenme yaklaşımının bir ilköğretim okulunda nasıl algılandığı ve uygulandığını ortaya çıkarmayı amaçlamıştır. Araştırmada nitel araştırma yöntemlerinden görüşme, gözlem ve doküman incelemesi kullanılarak veri toplanmıştır. Araştırma sonuçlarına göre projelerin öğrencilerin derslere olan motivasyonunu arttırdığı ve öğrenmelerini daha kalıcı kıldığı tespit edilmiştir. Ayrıca öğrencilerin yaratıcılıklarının ve el becerilerinin geliştiği gözlenmiştir.

Vaiz (2003), çalışmasında, ilköğretim 3. sınıf Hayat Bilgisi dersine ilişkin proje tabanlı öğrenme yaklaşımına dayalı öğrenci gelişim dosyaları kullanımının öğrenme sürecine ne şekilde yansıdığını ortaya koymayı amaçlamıştır. Araștırma sonunda; öğrencilerin Hayat Bilgisi dersine ayırdıkları haftalık çalışma sürelerinin arttığı, geliştirilen portfolyoların değerlendirme puanları ile sınıf öğretmeninin yaptığı sınavlar ile gözlem 
puanları arasında ve öğretmen ile velilerin kendi kendini değerlendirme puanları arasında anlamlı bir ilişki olduğu tespit edilmiştir.

Yurtluk (2003), proje tabanlı öğrenme yaklaşımının, Matematik dersi öğrenme süreci ile öğrenci tutumlarına etkisini araştırmıştır. Öğrencilerin çalışmaya ilişskin görüşleri değerlendirildiğinde derslerin daha zevkli ve yararlı geçtiği, diğer derslerle ilişkilerin kurulduğu, sorumluluk duygusunun geliştiği görülmüştür. Ayrıca çalışmaların sonunda öğrencilerde başarı duygusunun ortaya çıktığı gözlenmiş ancak öğrencilerin tutumlarında bir değişiklik gözlenmemiştir.

Özdener ve Özçoban (2004) tarafından yapılan çalışmada bilgisayar dersinde proje tabanlı öğrenme ile klasik öğrenme modeli karşılaştırılmıştır. İlköğretim altıncı sınıf öğrencilerinden 75 kişilik bir grup üzerinde yapılan çalışma sonunda proje tabanlı öğrenme modelinin öğrenci başarısı üzerinde olumlu etkisinin olduğu ve öğrencilerin bireysel ilgi ve yeteneklerine uygun öğretim yöntemi seçilmesi gerektiği belirlenmiştir.

Sidman-Taveau (2005), yaptığı çalışmada bilgisayar destekli proje tabanlı öğrenmenin İngilizceyi ikinci dil olarak öğrenen yetişkinlerin başarısına etkisini araştırmış ve proje tabanlı öğrenme uygulamalarının, deneklerin dil becerilerini birçok yönden geliştirdiği sonucuna varmıştır.

Çiftçi'nin (2006) çalışmasında ilköğretim 6. sınıf Sosyal Bilgiler öğretiminde proje tabanlı öğrenmenin, öğrencilerin akademik risk alma düzeyleri, problem çözme becerileri, erişileri, öğrenilenlerin kalıcılığı ve derse karşı tutumlarına etkisi incelenmiştir. Proje tabanlı öğrenmenin dersin kalıcılık düzeyi ve erişiye olumlu etki ettiği, öğrencilerin Sosyal Bilgiler dersine karşı tutumlarına etkisinin olmadığı tespit edilmiştir.

Yavuz’un (2006) çalışmasında Proje Tabanlı Öğretimin, çevre ve çevre koruma konusunda öğrencilerin çevre bilgileri, çevreye karşı tutumları ve davranışları üzerine olan etkisi belirlenmeye çalışılmıştır. Çalışma sonunda Proje Tabanlı Öğrenmeyle öğrencilerin çevre hakkındaki bilgilerinin arttırılabileceği ve bu konudaki tutumları ile davranışlarının geliştirilebileceği sonucuna ulaşılmıştır.

Yılmaz'ın (2006) çalışmasında Sosyal Bilgiler eğitiminde proje tabanlı öğrenmenin öğrenenlerin akademik başarıları, yaratıcılıkları ve tutumları üzerine etkisi incelenmiştir. Çalışma sonunda öğrencilerin başarı düzeylerinin arttığı, Sosyal Bilgiler dersine karşı tutumlarının yükseldiği ve yaratıcılık düzeylerinin de arttığı tespit edilmiştir.

Proje tabanlı öğretimle ilgili çalışmaların büyük çoğunluğunun fen bilimleri eğitimi alanında yapıldığı ancak yakın dönemlerde sosyal bilgiler 
alanında da bazı çalışmaların olduğu görülmektedir. Araştırma sonuçlarının geneline bakıldığında ise projelerin, öğrencilerin öğrenmelerine olumlu katkıda bulunduğu, öğrenilenlerin kalıcılığını arttırdığı, öğrencilerin derse yönelik tutumlarına - bütün çalışmalarda olmamakla birlikte - olumlu etkisinin olduğu ve öğrencilerin iletişim ve girişimcilik gibi sosyal becerilerini arttırdığı anlaşılmaktadır.

\section{Proje Tabanlı Öğretimin Türkçe Öğretiminde Kullanımı}

"Projeler, uygulamada karşılaşılan önemli dil/edebiyat problemlerinin bilimsel bilgiler yardımı ile bir öğrenme grubu tarafından aktif ve iş birlikçi bir şekilde çözüldüğü ders birimleridir. Bu yolla bilgi edinimi yanında problem çözme yöntemleri de öğrenilmektedir.” (Müller-Michaels, 1980'den aktaran Yıldız, 2003: 37). Bu doğrultuda öğrencilerin gerek dil becerilerindeki problemlerini çözmede gerekse öğrencilere dil yapılarının kavratılmasında proje tabanlı öğretimden yararlanılabilir.

Öğrencinin bilişsel ve duyuşsal yönden gelişmesine pek çok katkıda bulunduğu görülen proje tabanlı öğretimden Türkçe öğretiminde de yararlanılmalıdır. Özellikle öğrencilerin yazma ve konuşma becerilerinin geliştirilmesinde proje tabanlı öğretimin doğrudan etkisi olacaktır. Öğrenciler hazırladıkları projeleri yazılı bir metin haline getirecekler, yazılı ya da sözlü olarak sunacaklar ve böylece bu becerilerini geliştireceklerdir. Projeleri hazırlama sürecinde de birçok materyali okuyacaklar, kendilerine gerekli olanları seçecekler; yerine göre kaynak kişileri, öğretmenlerini ve arkadaşlarını dinleyeceklerdir. Özellikle yeni İlköğretim Türkçe Dersi 6-8. Sinıflar Öğretim Programı'nda (2006) temel dil becerileri olarak alınan konuşma, dinleme, okuma ve yazma eğitiminde proje tabanlı öğretimin hem her becerinin geliştirilmesinde ayrı ayrı hem de bütüncül olarak kapsamlı bir şekilde kullanılabileceği söylenilebilir.

İlköğretim okulları ikinci kademede verilen Türkçe eğitimi, dört temel dil becerisi ile dil bilgisi alanlarındaki kazanımların gerçekleştirilmesini öngörmektedir. Bu kazanımlarla öğrencilerin, dil becerilerinin geliştirilmesi amaçlandığı gibi aynı zamanda Türkçe dersinin genel amaçlarına ulaşmaları da beklenmektedir. "Duygu, düşünce ve hayallerini sözlü ve yazılı olarak etkili ve anlaşılır biçimde ifade etme", "Türkçeyi, konuşma ve yazma kurallarına uygun olarak bilinçli, doğru ve özenli kullanma", "Seviyesine uygun eserleri okuma; bilim, kültür ve sanat etkinliklerini seçme, dinleme, izleme alışkanlığı ve zevki kazanma", "Okuduğu, dinlediği ve izlediğinden hareketle, söz varlığını zenginleştirerek dil zevki ve bilincine ulaşma; duygu, düşünce ve hayal dünyalarını geliştirme" gibi genel amaçların (MEB, 2006: 4), temel dil becerilerine ilişkin kazanımlar yoluyla yerine getirilmesi mümkün olabilir. Ancak "Anlama, sıralama, ilişki kurma, sınıflama, 
sorgulama, eleştirme, tahmin etme, analiz-sentez yapma, yorumlama ve değerlendirme becerilerini geliştirme", "Yapıcı, yaratıcı, akılcı, eleştirel ve doğru düşünme yollarını öğrenme, bunları bir alışkanlık hâline getirme", "Bilgiye ulaşmada kitle iletişim araçlarından yararlanma, bu araçlardan gelen mesajlara karşı eleştirel bakış açısı kazanma ve seçici olma" genel amaçlarının (MEB, 2006: 4) gerçekleştirilebilmesinde yalnızca dil becerilerini geliştirmeye yönelik kazanımların yeterli olduğunu söylemek güçtür. Bunun için bazı ilave etkinliklere ve daha kapsamlı stratejilere ihtiyaç vardır. Öğrencilere hazırlatılacak proje etkinlikleriyle bu kazanımların gerçekleşebileceği söylenebilir.

Türkçe dersi öğretim programında (MEB, 2006: 235) "Değerlendirme Araç ve Yöntemleri" arasında proje ödevine de yer verilmiştir. Programda (MEB, 2006: 237) proje ödevlerinin nasıl hazırlatılacağı ve değerlendirileceği hakkında bilgiler verildikten sonra öğrencilerin proje seçmede sıkıntı yaşayabilecekleri ve sadece bilişsel düzeydeki etkinlikleri seçebilecekleri ifade edilmiş, projelerin kullanımında riskleri en aza indirmeye özen göstermenin gerektiği belirtilmiştir.

Millî Eğitim Bakanlığı tarafından hazırlanan Yedinci Sınıf Türkçe Ders Kitabı'nda (Altan vd., 2007: 272-275) da bir proje ödevi yer almaktadır. Bu projenin nasıl uygulanacağı, öğretmenler ve öğrenciler için hazırlanan yönergeyle aşama aşama açıklanmıştır. Projeye ilişkin bilgiler ana hatlarıyla şunlardır:

Konu: Illetişim Sorunları ve Çözüm Yolları

Içerik Düzeyi: İletişim

Beklenen Performans: Yaratıcı düşünme, problem çözme, araştırma yapma, karar verme, bilgi teknolojilerini kullanma, grupla çalışma.

Süre: 6 hafta

Değerlendirme: Dereceli puanlama anahtart

Kaynaklar: Internet, kitap, dergi, yazllı kaynaklar, tiyatro oyuncularl, yazarlar vb. kişiler.

Öğretmen İçin Ödev Yönergesi

1. Öğrencilerinizden "Illetişim Sorunları ve Çözüm Yolları" konulu bir piyes hazırlamalarını isteyiniz. Öğretmen Kılavuz Kitabı'ndaki ödev yönergesi ile dereceli puanlama anahtarını fotokopiyle çoğaltarak Türkçe dersinden proje ödevi alan ögrencilerinize veriniz.

2. Öğrencilerinizin sınıfta 3-4 grup oluşturmalarını ve kendilerine verilen ödev yönergesine göre çalışmalarını yürütmeleri isteyiniz. Öğrencilerinize hazırlanmaları için 6 hafta süreleri olduğunu söyleyiniz.

3. Ögrencilerinize piyes türü hakkında bilgi veriniz. 
4. Öğrencilerinize çalışmaları süresince aşamadı̆̆ engelleri aşmaları için yardım ediniz. Özellikle piyesin sergileneceği sahnenin hazırlanması aşamasında okul idaresiyle iletişim kumalarını sağlayınız.

5. Öğrencilerinizin çalışmalarını dereceli puanlama anahtarını kullanarak değerlendiriniz. Bu çalışmadan alınabilecek en yüksek puan 12, en düşük puan ise 5'tir. Öğrencilerinizin aldıkları puanları 5'lik not sistemine dönüş̧ürebilirsiniz.

Ögrenciler İçin Ödev Yönergesi

Sevgili öğrenciler! İletişim sorunlarını çoğu kez hayatımızı güçleştirmektedir. Sizden hayatımızı güçleştiren iletişim sorunlarını ve bu sorunların çözüm yollarını düşünerek arkadaşlarınıza sunmak üzere bir piyes yazmanı ve piyesinizi sunmanı beklenmektedir. Bu çalışma sizin yaratıcı düşünme, problem çözme, araştırma yapma, karar verme ve bilgi teknolojilerini kullanma becerilerinizin gelişmesine katkıda bulunacaktır.

Bu çalışmayl yaparken izleyeceğiniz yol:

1. Sinıfinızda 3-4 grup oluşturunuz.

2. Grup başkanını seçiniz.

3. Yapacağınız çalışmanın planını oluşturunuz.

4. IŞS bölümü yapınız. İ̧s bölümü yaparken aşağıdaki aşamaları göz önünde bulundunuz.

a. Insan hayatını güçleştiren iletişim sorunlarını gözlemleyiniz.

b. Bu sorunların kaynağını araştırınız.

c. Bu sorunları nasıl çözebileceğinizi düşününüz.

d. Çeşitli piyes örneklerini inceleyiniz.

e. Piyes metnini yazını.

f. Piyesinizi canlandırmak için rol dă̆ılımı yapınız.

g. Piyesinizi canlandıracağınız mekânı, piyeste kullanacă̆ınız kostümleri ve fon müziklerini hazırlayını.

h. Öğretmeninizin size duyurduğu tarihte piyesinizi sununuz.

Çalışmanız sırasında ögretmenlerinizden yardım isteyebilirsiniz. Çalışmanızı hazırlarken varsa, yaşadığınız yerdeki üniversitelerin tiyatro bölümlerine, özel, devlet veya çeşitli kurum ve kuruluşlara ait tiyatrolara giderek konuyla ilgili bilgi edinebilirsiniz.

Okutulmakta olan diğer kitaplarda da çeşitli proje ödevlerine yer verilmektedir. Bu yolla hem öğrencilerin dil becerilerinin çok yönlü olarak gelişimine destek olunmakta hem de yeni beceriler kazanmalarına firsatlar sunulmaktadir. 


\section{Sonuç ve Öneriler}

Proje tabanlı öğretim, günümüzde yapılandırmacı anlayışla hazırlanan öğretim programlarına uygun olarak öğrencilerin bilgiyi kendilerinin oluşturmasına dayanması yönüyle önemlidir. Bu şekilde öğrenci, yaşayarak ve öğrenmede etkin rol alarak öğrenmektedir. Proje tabanlı öğretim, öğrencilerin; bir ürün ortaya koyma yönüyle öz güven kazanma ve karar verme, kendi başına ya da akranlarıla birlikte iş yapma becerisi edinme yönüyle de toplumsallaşma yönlerinden gelişmelerini sağlayacaktır. Bunların yanında Proje Tabanlı Öğretimin, temel dil becerilerinin geliştirilmesinde hem her becerinin geliştirilmesinde ayrı ayrı hem de bütüncül olarak kapsamlı bir şekilde kullanılabileceği söylenilebilir.

Proje tabanlı öğretimin bir ünite ya da tema çerçevesinde gerçekleştirilmesi faydalı olacaktır. Projenin planlanması ve geliştirilmesi tamamıla öğretmen ve öğrencilere bırakılmamalıdır. Dersin hangi konusunun ya da programda belirlenen kazanımların hangilerinin proje tabanlı öğretimle daha etkili ve verimli gerçekleştirileceği uzmanlar tarafından - deneysel çalışmalarla - belirlenmelidir. Öğretmenler de uzmanlar tarafindan geliştirilen bu yapıda kendilerine ve öğrencilerine uygun küçük değişiklikler yaparak projeyi uygulamaya koymalıdır.

Proje tabanlı öğretimin, doğru yapılandırıldığı zaman Fen Bilgisi (Fizik, Kimya, Biyoloji), Bilgisayar, Hayat Bilgisi, Sosyal Bilgiler ve Coğrafya gibi derslerin yanında Türkçe derslerinde de etkili bir biçimde kullanılabileceği söylenebilir. Özellikle yeni Türkçe Öğretim Programının tematik özellikte olması, proje tabanlı öğretimin daha kolay uygulanmasını sağlayabilir. Ders kitaplarındaki etkinlikler ve ödevler yoluyla Türkçe derslerinde proje tabanlı öğretimden daha kapsamlı ve etkili bir biçimde yararlanma yoluna gidilmelidir.

\section{KAYNAKLAR}

Alnıak Ş. ve Yılmaz, H. (2004). Kuramsal Bakış Açısıyla Proje Yaklaşımı. Eğitim Araştırmaları. 17: 92-101.

Altan, A., Arhan, S., Başar, S., Özaykut, S., Öztürker, G., Yılmaz, D. ve Yüksel, Y. (2007). Türkçe Öğretmen Kılavuz Kitabı. Ankara: Millî Eğitim Bakanlığı Yayınları.

Çiftçi, S. (2006). Sosyal Bilgiler Öğretiminde Proje Tabanlı Öğrenmenin Öğrencilerin Akademik Risk Alma Düzeylerine, Problem Çözme Becerilerine, Erişilerine, Kalıcılığa ve Tutumlarına Etkisi. Konya: Selçuk Üniversitesi Sosyal Bilimler Enstitüsü (Yayımlanmamış Doktora Tezi). 
Demirel, Ö. (2003). Kuramdan Uygulamaya Eğitimde Program Geliştirme. Ankara: Pegem A Yayıncılık.

Demirhan, C. (2002). Program Geliştirmede Proje Tabanlı Öğrenme Yaklaşımı. Ankara: Hacettepe Üniversitesi Sosyal Bilimler Enstitüsü (Yayımlanmamış Yüksek Lisans Tezi).

Erdem, M. (2002). Proje Tabanlı Öğrenme. Hacettepe Üniversitesi Eğitim Fakültesi Dergisi. 22: 172-179.

Erdem, M. ve Akkoyunlu, B. (2002). İlköğretim Sosyal Bilgiler Dersi Kapsamında Beşinci Sınıf Öğrencileriyle Yürütülen Ekiple Proje Tabanlı Öğrenme Üzerine Bir Çalışma. İlköğretim-Online. 1 (1): 2-11. http://ilkogretim-online.org.tr/vol1say1/v01s01a.pdf

Fleming, D. S. (2000). A Teacher's Guide to Project-Based Learning. Washington: Office of Educational Research and Improvement. www.eric.ed.gov (Eric Number ED469734)

Girgin Balkı, A. (2003). Proje Temelli Öğrenme Yönteminin Özel Konya Esentepe İlköğretim Okulu Tarafindan Uygulanmasına Yönelik Bir Değerlendirme. Konya: Selçuk Üniversitesi, Sosyal Bilimler Enstitüsü (Yayımlanmamış Yüksek Lisans Tezi).

Kaptan, F. ve Bozkurt R. (2002). Fen Eğitiminde Proje Tabanlı Öğrenme Yaklaşımı. Çağdaş E ğitim Dergisi. 287: 18-28.

Kaptan, F. ve Korkmaz, H. (2002). Fen Eğitiminde Proje Tabanlı Öğrenmenin Yaratıcı Düşünme, Problem Çözme ve Akademik Risk Alma Düzeylerine Etkisi. Hacettepe Üniversitesi E ğitim Fakültesi Dergisi. 22: 164-170.

Kılıç, Z. (2004). Meslek Eğitiminde Projeye Dayalı Öğretimin Öğrencilerin Akademik Başarılarına ve Bilgilerinin Kalıcılığına Etkisi. Ankara: Gazi Üniversitesi Eğitim Bilimleri Enstitüsü (Yayımlanmamış Yüksek Lisans Tezi).

Korkmaz, H. (2002). Fen Eğitiminde Proje Tabanı Öğrenmenin Yaratıcı Düşünme, Problem Çözme ve Akademik Risk Alma Düzeylerine Etkisi. Ankara: Hacettepe Üniversitesi Sosyal Bilimler Enstitüsü (Yayımlanmamış Doktora Tezi).

MEB (2006). İlköğretim Türkçe Dersi 6-8. Sınıflar Öğretim Programı. Ankara: MEB Yayınları.

Özdemir, E. (2006). Proje Tabanlı Öğrenmenin Öğrencilerin Geometri Başarılarına Ve Geometriye Yönelik Tutumlarına Etkisinin Araştırılması. Ankara: Orta Doğu Teknik Üniversitesi Fen Bilimleri Enstitüsü (Yayımlanmamış Yüksek Lisans Tezi). 
Özdener, N. ve Özçoban, T. (2004). Bilgisayar Eğitiminde Çoklu Zekâ Kuramına Göre Proje Tabanlı Öğrenme Modelinin Öğrenci Başarısı Üzerine Etkisi. Kuram ve Uygulamada Eğitim Bilimleri. 4 (1), 147 170.

Saban, A. (2002). Öğrenme Öğretme Süreci Yeni Teori ve Yaklaşımlar. Ankara: Nobel Yayın Dağıtım.

Sidman-Taveau, R. L. (2005). Computer Assisted Project Based Learning in Second Language: Case Studies in Adult ELS. The University of Texas, Unpublished $\mathrm{PhD}$ Thesis.

Taşpınar, M. (2005). Kuramdan Uygulamaya Öğretim Yöntemleri. Elazığ: Üniversite Kitabevi.

TDK (2005). Türkçe Sözlük. Ankara: Türk Dil Kurumu Yayınları.

Toci, M. J. (2000). The Effect of a Technology-Supported, Project-Based Learning Environment on Intrinsic and Extrinsic Motivational Orientation. The Pennsylvania University, Unpublished $\mathrm{PhD}$ Thesis.

Vaiz, O. (2003). Proje Tabanlı Öğrenmede Portfolyoların Kullanımı ve Öğrenme Sürecine Yansımaları. Ankara: Hacettepe Üniversitesi Sosyal Bilimler Enstitüsü (Yayımlanmamış Yüksek Lisans Tezi).

Yavuz, K. E. (2005). Aktif Öğrenme Yöntemleri. Ankara: Ceceli Yayınları.

Yavuz, S. (2006). Proje Tabanlı Öğrenme Modelinin Kimya Eğitimi Öğrencilerinin Çevre Bilgisi İle Çevreye Karşı Tutumlarına Olan Etkisinin Değerlendirilmesi. Ankara: Hacettepe Üniversitesi Fen Bilimleri Enstitüsü (Yayımlanmamış Doktora Tezi).

Yıldız, C. (2003). Türkçe Öğretiminde Alternatif Yöntemler. Ankara: Anı Yayincilik.

Yılmaz, O. (2006). İlköğretim 7. Sınıf Sosyal Bilgiler Dersinde Proje Tabanlı Öğrenmenin Öğrenenlerin Akademik Başarıları, Yaratıcılıkları ve Tutumlarına Etkisi. Zonguldak: Zonguldak Karaelmas Üniversitesi Sosyal Bilimler Enstitüsü (Yayımlanmamış Yüksek Lisans Tezi).

Yurtluk, M. (2003). Proje Tabanlı Öğrenme Yaklaşımının Matematik Dersi Öğrenme Süreci Ve Öğrenci Tutumlarına Etkisi. Ankara: Hacettepe Üniversitesi Sosyal Bilimler Enstitüsü (Yayımlanmamış Yüksek Lisans Tezi).

Yurtluk, M. (2005). Proje Tabanlı Öğrenme. Demirel, Ö. (Ed.), Eğitimde Yeni Yönelimler içerisinde. Ankara: PegemA Yayıncılık. 